\title{
Personalized Marketing of Health Products the 21st Century Way
}

Joseph Turow

University of Pennsylvania, jturow@asc.upenn.edu

Robert Gellman

Judith Turow

Follow this and additional works at: https://repository.upenn.edu/asc_papers

Part of the Health Communication Commons

\section{Recommended Citation}

Turow, J., Gellman, R., \& Turow, J. (2007). Personalized Marketing of Health Products the 21st Century Way. AMA Journal of Ethics, 9 (3), 206-209. Retrieved from https://repository.upenn.edu/asc_papers/645

The AMA Journal of Ethics was formerly titled Virtual Mentor (until 2015).

This paper is posted at ScholarlyCommons. https://repository.upenn.edu/asc_papers/645

For more information, please contact repository@pobox.upenn.edu. 


\section{Personalized Marketing of Health Products the 21st Century Way}

\section{Disciplines}

Communication | Health Communication | Social and Behavioral Sciences

\section{Comments}

The AMA Journal of Ethics was formerly titled Virtual Mentor (until 2015). 


\section{Virtual Mentor}

American Medical Association Journal of Ethics

March 2007, Volume 9, Number 3: 206-209.

\section{Policy forum}

Personalized marketing of health products the 21st century way

by Joseph Turow, PhD, Robert Gellman, JD, and Judith Turow, MD

New technologies are providing health care marketers with more and more mouthwatering opportunities that are legal but may not be ethical and could be dangerous. Marketers already have the ability to gather and compile health-related information from adults and teens without their knowledge. Now they are building the capacity to engage in one-to-one advertising that combines the data they have collected with other available consumer information. Over time these activities will inevitably affect physicians' relationships with their patients and, eventually, the custom-made stories marketers tell people about their bodies may become more influential than medical advice from doctors.

Makers of pharmaceuticals, over-the-counter drugs and medical appliances already buy lists of people with various ailment profiles so that they can advertise to them directly. Although HIPAA (Health Insurance Portability and Accountability Act) regulations generally prohibit physicians and health care facilities from releasing information about patients for the purpose of marketing, consumers searching for information often respond to Web sites, magazine questionnaires, advertisers and merchants that are not bound by the health privacy law. Questions about individual and household ailments may be sandwiched among mundane questions about clothes or cars, and the average person is rarely aware of the consequences of sharing such personal information. Those who collect the information can then use it or sell it to firms that maintain consumer profiles and offer mailing lists.

A simple Web search to one of many "list finder" sites will give you an idea of just how extensive these health-related lists are. Seconds after typing "ailment sufferers" into the search box, you will see links to firms that will sell postal, e-mail and telephone contacts for millions of individuals with disease profiles [1]. Some list purveyors claim to deliver names of general "chronic ailment sufferers," while others offer lists sorted by diagnoses as varied as angina, breast cancer, eating disorders, acne and baldness. One seller boasts that, "These consumers are highly responsive to offers such as: subscriptions, fundraising, mobility aids and various other types of medical products and services” [1]].

It is fair to assume that today's methods for identifying and cultivating prospective users of health products will seem primitive several years from now. That is because media firms will be able to track activities of individual audience members, compile behavioral and other information in databases, and then use mass customization 
technologies to tailor ongoing messages for particular audience members based on the data profiles. The possibility of locating likely customers efficiently and then communicating with them during their most persuadable moments represents a marketer's nirvana.

Cable companies already track what viewers watch with digital set boxes. Mobile phone companies know where their customers are calling from and where the calls are going. Google, Microsoft, Yahoo! and many Web sites store data about customers' searches and click patterns and, if the users have registered, these companies know (and can buy) other information about them. Moreover, rabid competition and increasingly sophisticated computer analyses are pushing media firms toward exploiting as much of their data as possible. The firm Visible World has worked with Cablevision to test and send slightly different commercials to cable households based on the demographics of their members.

The public's concerns about privacy do not hinder these activities. Media outlets can transmit a pharmaceutical firm's ads to target consumers, for example, without the pharmaceutical company's knowing their names or addresses. If it wants to, the company can then discover who its potential customers are by providing attractive incentives (discounts, free drugs, newsletters) to those who answer the ad. By phoning or clicking, the customer waives his or her anonymity, gets added to the company's own unregulated database, and unwittingly exposes personal information for resale or reuse.

\section{Personal health records}

Merge people's shopping, viewing and surfing histories with their personal health records (PHRs), and you have a bonanza of exploitable marketing information. Electronically organizing and storing personal medical information is a growing business. Commercial PHR services may lie outside the scope of HIPAA and other laws intended to protect privacy depending on how they are established and who is running them. Operators of unregulated PHR services can use and disclose records without restriction. Some consumers see the benefits of electronically accessible health records, such as immediate and portable access to medical information in an easy-to-use format, but are unwilling to pay for them, which opens the door for advertising-supported PHR firms and the likelihood that some patient data will be available to marketers. Employer-sponsored PHRs may also expose consumers to privacy risks.

With cutting-edge database and media technologies, companies are able to surround likely targets with articles, programs and commercials tailored to the informationrich profiles that the marketers and media have about them. Large pharmaceutical firms, for example, will find it cost-effective to send customized network television and video game ads to people who might be considering non-generic versions of their drugs. Or they might find it profitable to pay for TV characters to mention products in those homes where possible patients live. In coming decades the costs of reaching small slices of national audiences may become so competitive that 
controversial, even dangerous, interest groups will work the niche-marketing terrain with little, if any, regulation. Teenage girls who buy lots of chewing gum and nocalorie cola, for example, might be bombarded by customized cable commercials, Web ads and supermarket coupons for diet pills. Pro-anorexia groups might pursue these diet-inclined teens on the Web and via cell phone links. Companies that bank umbilical cord blood for the treatment of childhood cancer might send testimonials to pregnant women through a range of cost-efficient media. Advocates against childhood vaccinations might present tales of woe to women who search the Web for child-related information, seek kid-clothing stores through their mobile phone search engines, or have e-mailed a friend via a service that tracks e-mail contents and then posts content-related ads.

These sorts of custom-made ads and testimonials provide individuals with selected information about their bodies and health care options when they are most vulnerable. Most of the time, the ad recipients probably don't know how to identify or evaluate the source. Even if they do understand what is happening, they will most likely not be aware that complex databases-undoubtedly with inaccurate as well as accurate information-triggered the medical messages that surround them.

Unfortunately, these messages may well be more consistent, frequent and even personalized than instructions from professional caregivers, whom consumers see infrequently. Physicians and other health professionals who object strongly to elements of these ad campaigns are unlikely to know which niche messages reach which patients, so they will be ill-prepared to counteract them.

The good news is that we are only at the start of this revolution in health care marketing. Health professionals have time to consider its implications and plan responses. Individual physicians might find time to talk to patients about medical ads that they receive or view. Medical organizations, patient groups and, perhaps, regulators can work to prohibit all PHR firms from selling or sharing their data for marketing purposes. Outside pressure can also help media firms address ethics and self-regulation regarding customized health-related ads and program insertions. Selfregulation should involve the critical examination of policies on privacy and database categories. Google's privacy policy, for example, states that it does not store an individual's "sensitive medical information," but it doesn't explain what that means. It should.

We are moving into an information world with great opportunities as well as potential pitfalls for the public's understanding of its health. If physicians and consumers prepare for the dark side of database marketing as well its more positive aspects, they can diminish the chances that the new environment will adversely affect patients' well-being. 


\section{Reference}

1. Chronic ailment sufferers list. Direct Magazine. Available at: http://listfinder.directmag.com/ market;jsessionid=557B6D6EDD64A6504C7E9BAF8AFE9558?page=resear ch/search_results. Accessed January 5, 2007.

Joseph Turow, PhD, is the Robert Lewis Shayon Professor of Communication and associate dean for graduate studies at the University of Pennsylvania's Annenberg School for Communication in Philadelphia. His newest book explores the social implications of database marketing in the fragmented media environment.

Robert Gellman, JD, is a privacy and information policy consultant in Washington, D.C., and formerly served as chief counsel to the Subcommittee on Government Information in the House of Representatives.

Judith Turow, MD, is a pediatrician at the offices of the Alfred I. duPont Hospital for Children in Philadelphia. She is also a clinical assistant professor of pediatrics at Thomas Jefferson University Hospital in Philadelphia.

The viewpoints expressed on this site are those of the authors and do not necessarily reflect the views and policies of the AMA.

Copyright 2007 American Medical Association. All rights reserved. 